\title{
Relationship between exposure to the Avahan intervention and levels of reported condom use among men who have sex with men in southern India
}

Kate M Mitchell ${ }^{1,8^{*}}$, Anna M Foss ${ }^{1}$, Banadakoppa M Ramesh ${ }^{2,3}$, Reynold Washington ${ }^{2,3}$, Shajy Isac ${ }^{2,3}$, Holly J Prudden', Kathleen N Deering ${ }^{4}$, James F Blanchard ${ }^{3,5}$, Stephen Moses ${ }^{3,5}$, Catherine M Lowndes ${ }^{6,7}$, Marie-Claude Boily ${ }^{8}$, Michel Alary ${ }^{7}$ and Peter Vickerman ${ }^{1,9}$

\begin{abstract}
Background: The Avahan intervention promotes consistent (100\%) condom use amongst men who have sex with men in southern India. We assessed how condom use varies with intervention exposure for men who have sex with men in Bangalore.

Methods: Self-reported condom use and intervention exposure data were derived from a cross-sectional survey. Consistent condom use and condom use at last sex act with all, main, and casual male sex partners were assessed. Binary and continuous variables reflecting intervention exposure (including contact(s) with intervention staff, receiving condoms and seeing condom demonstrations) were used. Multivariable logistic regression was employed to assess the relationship between condom use with each type of partner and each exposure variable independently, controlling for socio-demographic and behavioural factors associated with condom use or intervention exposure.
\end{abstract}

Results: Condom use with all partners was higher among those who had ever been contacted by, received condoms from, or seen a condom demonstration by intervention staff (adjusted odds ratio $>2, p<0.02$ for all). Consistent condom use with all types of partner increased with the number of condom demonstrations seen in the last month (adjusted odds ratio $=2.1$ per demonstration, $\mathrm{p}<0.025$ ), while condom use at last sex act with a casual (but not main) partner increased with the number of condoms received from the intervention (adjusted odds ratio $=1.4$ per condom, $p=0.04)$.

Conclusions: Direct contact with Avahan program staff is associated with increased reported condom use among men who have sex with men in Bangalore. Reported consistent condom use and condom use at last sex act are associated with contacts involving demonstrations of correct condom use, and with receiving condoms, respectively.

Keywords: Consistent condom use, Condom use at last sex act, Condom demonstration, Key population, Bangalore, Cross-sectional study, Logistic regression

\footnotetext{
* Correspondence: Kate.Mitchell@imperial.ac.uk

'Department of Global Health and Development, London School of Hygiene

and Tropical Medicine, London, UK

${ }^{8}$ Current address: Department of Infectious Disease Epidemiology, Imperial

College London, London, UK

Full list of author information is available at the end of the article
} 


\section{Background}

Condoms are highly protective against HIV transmission when used consistently and correctly [1-4]. The India AIDS Initiative (Avahan) of the Bill \& Melinda Gates Foundation, an HIV prevention program which targets populations at high risk of HIV acquisition in the highest HIV prevalence states in India, aims to directly reduce HIV transmission among and from these high-risk groups by treating bacterial sexually transmitted infections (STIs) and promoting consistent condom use (CCU) $[5,6]$. One of the high-risk groups targeted is men who have sex with men (MSM), a marginalised group in southern India, known to have high HIV prevalence $(7-21 \%$ in different districts of Andhra Pradesh, Maharashtra, Tamil Nadu and Karnataka states [7-10]). Surveys of MSM across southern India have suggested high levels of engagement in commercial sex [7-9], with 40-68\% of MSM in different surveys reporting ever receiving payment for sex $[7,9]$. Much smaller numbers of MSM (3-7\%) report sex work as their main source of income, excepting Karnataka state where $57 \%$ of MSM surveyed reported sex work as their main income source $[7,10]$. It should be noted that these surveys tend to capture higher-risk MSM, and so they are likely to overestimate the true proportion of MSM who sell sex [11].

Evaluation of the impact of the Avahan intervention has been challenging; there is no control group (for ethical and logistical reasons), and baseline surveys were carried out some time after the intervention started $[6,12,13]$. Several approaches have been used to estimate how Avahan has affected condom use [13-18]. One analysis found that in Karnataka state, reported levels of CCU by female sex workers (FSWs) with their commercial clients was higher among FSWs who reported contact with the Avahan intervention [16]. It also found that condom use increased with time since initial contact with the intervention, with increased numbers of contacts with program outreach staff, and (more strongly) with the number of condom demonstrations witnessed, in a dose-dependent manner [16]. Such analyses can be used to inform calculations of the cost-effectiveness of different intervention options, for example the relative impact of more intense interventions reaching fewer high-risk individuals compared with less intense interventions reaching more people [19].

Here, we performed a similar analysis for self-reported condom use among MSM in Bangalore, southern India, to see whether contact with the Avahan intervention was linked to an increased level of self-reported condom use with different male sexual partners. In Bangalore, Avahan services were delivered to MSM by a local nongovernmental organisation (NGO), Sangama. Sangama had been working with local MSM for some years previously, promoting sexual minority rights, and had been delivering Avahan HIV-prevention services for about eleven months prior to the survey used here.

Since the previous study amongst FSWs suggested that different exposure measures, reflecting different aspects of the intervention, may vary in their relationship with condom use [16], we looked at a number of different measures of intervention exposure to identify the particular components of contact with the Avahan intervention which were associated with increased self-reported condom use by MSM.

\section{Methods}

\section{Data}

The data come from a cross-sectional Integrated Biological and Behavioural Assessment (IBBA), which was conducted in urban Bangalore, Karnataka in 2006 as part of the evaluation of Avahan [5,7,11]. Respondents provided blood samples for HIV and STI testing, and provided behavioural information through a structured faceto-face questionnaire. In Bangalore, since the Avahan intervention is delivered by local NGO Sangama, all questions about contact with Avahan refer to contact with Sangama. MSM were recruited by time-location sampling at local 'cruising sites' (locations where men are known to look for male sexual partners) [11]. Three hundred and twenty out of 554 MSM approached (58\%) completed the behavioural survey [20] and are included in this analysis. Standardized weights were assigned to the data to account for differences in selection probabilities between different clusters of MSM arising from the sampling design [7,11]; clusters were also taken into account, using the Complex Samples module in SPSS.

This research received approval from the Ethics Committee of the London School of Hygiene and Tropical Medicine. The Bangalore data collection methods were approved by the Ethics Review Boards of St Johns Medical College and Hospital, Bangalore, the Centre hospitalier affilié universitaire de Québec (CHA), Québec, Canada, and the University of Manitoba, Canada. For the monitoring and evaluation of the Avahan intervention in India, ethical approval was also obtained from the Ethics Review Board of the Centre hospitalier affilié universitaire de Québec, Québec, Canada.

\section{Outcome variables}

The outcome variables were: (1) reporting CCU (study participants responded that in general they used condoms "every time" rather than "most of the time", "sometimes", or "never"); and (2) reporting using a condom at last sex act, with each of the following types of partner: (i) all male sexual partners; (ii) main (regular) male sexual partner; (iii) casual ("new" or "unknown") male sexual partners. Only MSM who reported having sex with new or unknown partners in the past week were 
asked about condom use with casual partners in the survey. Although many MSM reported selling sex, the data collected in this survey did not differentiate between commercial and non-commercial partners, and so both 'all' and 'casual' partners are likely to reflect a mixture of commercial and non-commercial partnerships.

\section{Exposure variables}

Three binary variables reflecting exposure to the Avahan intervention were investigated: whether or not MSM had ever been contacted by community mobilizers/staff from Sangama; whether or not they had ever been given condoms by Sangama staff; and whether they had ever seen a demonstration of correct condom use by a Sangama worker. Four continuous exposure variables were also investigated: duration since first contact by Sangama staff (for those ever contacted); number of times contacted by Sangama staff in the last month (for those ever contacted); number of condoms received on the most recent occasion that they were given condoms by Sangama staff (for those who had ever received condoms); and number of condom demonstrations seen in the last month (for those who had ever seen a condom demonstration).

\section{Socio-demographic and behavioural variables}

A number of additional variables which might influence the relationship between intervention exposure and condom use were also examined for any relationship with either condom use or intervention exposure. All of the continuous variables were also considered as categorical variables, which were derived by dividing the data into quartiles, giving four groups of roughly equal sizes. The variables considered were: age (continuous variable or categorised into 16-22/23-25/26-31/32-60 years of age); duration as an MSM (calculated as time since first had sex with a man; continuous variable or categorised into 0-4/5-7/8-13/14+ years); ever married to a woman; ever paid a female for sex; religion (Hindu or other (Muslim or Christian)); circumcision status; literacy (whether or not they could read and write); school grade reached for those literate (categorised into 0-8/9-10/11-12/13-16); had ever sold sex; sex work being their main source of income; three sexual identity groups (Kothis + Hijras/ Panthis + bisexuals/double deckers (Kothis and Hijras mainly take the receptive role in anal sex, Panthis and bisexuals mainly take the insertive role, and double deckers take both roles [21-23]); location where sex usually occurs with male partners (public or private, where public $=$ bar/nightclub, public garden, public toilet, railway station, bus stop/stand, cinema hall/theatre or other public place, and private = home, rented room, vehicle, hammam or lodge); number of MSM partners having had anal sex with in the last week (continuous variable or categorised into 0/1-2/3-4/5+); number of times having had anal sex with known partners in the last week (continuous variable or categorised into 0/1-2/3/4+); and the number of times having had anal sex with new partners in the last week (continuous variable or categorised into $0 / 1-2 / 3-5 / 6+)$.

\section{Statistical analysis}

Logistic regression analyses were used to identify the factors associated with each of the outcome variables (condom use with each partner type, either at last act or consistently). First, we looked separately at the relationship between each outcome variable and each of the intervention exposure variables in univariate regression analyses. Second, we identified any socio-demographic and behavioural variables which were associated with either the outcome or the intervention exposure variables (i.e. potential confounding variables) using univariate regression - logistic regression for assessing associations with condom use variables and binary exposure variables, and linear regression for assessing associations with continuous exposure variables.

Separate multivariable logistic regression models were constructed for each outcome variable and each exposure variable, which included relevant confounding variables. Socio-demographic or behavioural variables were considered for inclusion in the multivariable models if the p-value for their association with either the exposure or the outcome variable was less than 0.1 . Since the variables reflecting sexual activity (number of partners in the last week, or number of sex acts with regular or new partners in the last week) were highly correlated, we identified the one which was most often associated with condom use - number of sex acts with new male partners in the last week (as a continuous variable) - and included this (and none of the other sexual activity variables) in all multivariable models. Since 'sex work as main income source' is a subset of 'ever sold sex', when both of these variables were associated with the outcome, the one most closely associated was included in multivariable models. All variables were entered simultaneously into the multivariable models.

Results were considered to be statistically significant if $\mathrm{p}<0.05$. All associations of the main exposure and outcome variables with socio-demographic and behavioural variables with a $\mathrm{p}$-value $<0.1$ are reported, as these variables were considered for inclusion in multivariate models.

All analyses were performed using IBM SPSS Statistics version 20.0.0.

\section{Results}

Population characteristics

The MSM surveyed had a mean age of 28 years old (range 16-60), and had been having sex with men for an 
average of 10 (range 0-37) years. Forty-one percent reported sex work as their main source of income, $76 \%$ were literate and $82.5 \%$ were Hindu. Fifty-one percent of the sample self-identified as Kothi or Hijra, 22\% as Panthi or bisexual and $27 \%$ as double deckers. One hundred and thirty-one MSM (41\%) reported a main male sexual partner and 238 (76\%) declared casual male partners. MSM reported an average of three (range 0-50) male sex partners in the past week. Twenty-four percent had ever been married to a woman, and $16 \%$ had ever paid a female for sex.

\section{Intervention exposure}

Seventy-two percent of MSM reported ever being contacted by Sangama staff, $67 \%$ had received condoms from Sangama, and 56\% had witnessed a condom demonstration. There was considerable overlap between these exposures; all of those who received condoms or seen a condom demonstration had also been contacted by the intervention, and 55\% of MSM reported all three of these exposures (they had been contacted, received condoms and seen a condom demonstration). Almost all (98\%) of those who had seen a condom demonstration also reporting receiving condoms. Among those contacted, there was a positive correlation between duration since first contact with Sangama and number of contacts in the last month $(\mathrm{r}=0.185, \mathrm{p}=0.005)$; this association persisted when only those who had first had contact with Sangama within the previous 11 months (since Sangama began offering Avahan services) were considered $(\mathrm{r}=0.211, \mathrm{p}=0.03, \mathrm{n}=106)$. No association was seen between the other continuous intervention exposure variables.

\section{Associations with socio-demographic and behavioural variables}

Men who had ever been contacted by Avahan were more likely to have ever sold sex than those who had never been contacted (odds ratio $(\mathrm{OR})=2.17, \mathrm{p}=0.010$ ). MSM who had ever (versus never) received condoms from Avahan were more likely to have ever sold sex $(\mathrm{OR}=2.23, \mathrm{p}=0.006)$ and less likely to have ever had sex with a female sex worker $(O R=0.51, p=0.083)$. Men who had ever (versus never) seen a condom demonstration were also more likely to have ever sold sex (OR = 2.26, $\mathrm{p}=0.005)$, and less likely to have ever had had sex with a female sex worker $(O R=0.50, p=0.038)$. Number of contacts with the intervention in the past week was associated with duration as an MSM (lowest for those who had been MSM for 8-13 years, highest for those who had been MSM for 14+ years), and was lower for those with sex work as their main income (1.5 fewer contacts per month, $\mathrm{p}=0.07)$. More condoms were received by those who had never paid a female for sex (versus ever; 56 more condoms, $\mathrm{p}=0.05)$, by those who had ever sold sex (94 more condoms, $\mathrm{p}=0.03)$, by those for whom sex work was their main source of income (149 more condoms, $\mathrm{p}=0.03$ ), and by Kothis and Hijras (versus other subgroups; 130 more condoms; $\mathrm{p}=0.01$ ). More condom demonstrations were reported by those who had never been married to a woman (versus ever; 1.4 more demonstrations per month, $\mathrm{p}=0.03)$, those who had never paid a female for sex (1.2 more per month, $\mathrm{p}=0.07)$, and by double deckers (2.6 more per month), and Kothis and Hijras (1.5 more per month) (versus Panthis and bisexuals; $\mathrm{p}=0.002$ ).

\section{Factors associated with CCU}

Seventy-one percent of MSM reported CCU with all male partners, 74\% reported CCU with their main male partner, and $74 \%$ reported CCU with casual male partners.

\section{Associations with socio-demographic and behavioural variables}

CCU with all partners was related to duration as an MSM (highest among those who had been MSM 5-7 years; $\mathrm{p}=0.051)$ and was higher among those who had ever sold sex $(p=0.003)$, those with sex work as their main income $(\mathrm{p}<0.001)$, and Kothi and Hijra $(\mathrm{p}=0.004)$. CCU with causal partners was also higher among those who had ever sold sex $(p=0.01)$, those with sex work as their main income $(\mathrm{p}<0.001)$, and among Kothi and Hijra $(\mathrm{p}=0.014)$, and was also higher amongst those having sex in private (versus public) locations $(\mathrm{OR}=2.0, \mathrm{p}=0.08)$. CCU was more closely associated with sex work as main income than ever selling sex, so 'sex work as main income' was included in multivariable models. Less $\mathrm{CCU}$ with main partners was reported by Hindus $(\mathrm{OR}=0.37, \mathrm{p}=0.08)$, and levels of CCU with main partners increased with increasing number of sex acts with new partners in the last week (OR per additional partner $=1.3, \mathrm{p}=0.01$ ).

\section{Unadjusted and adjusted associations with intervention exposure}

In unadjusted analyses, CCU with all partners was significantly higher among those who had been contacted by the Avahan intervention (77\% versus 55\%), those who had received condoms from the intervention (79\% versus $55 \%$ ) and those who had seen a condom demonstration (85\% versus $54 \%$ ) (Figure 1a-c). Even greater differences were seen between the exposed and unexposed MSM in CCU with specific partner types for each of these binary measures (Figure 1a-c). All of these associations remained significant after adjusting for socio-demographic and behavioural factors which were associated with either CCU or with intervention exposure (Table 1). CCU was not associated with duration since first intervention contact or number of contacts with the intervention in the past 
(a) Intervention contact

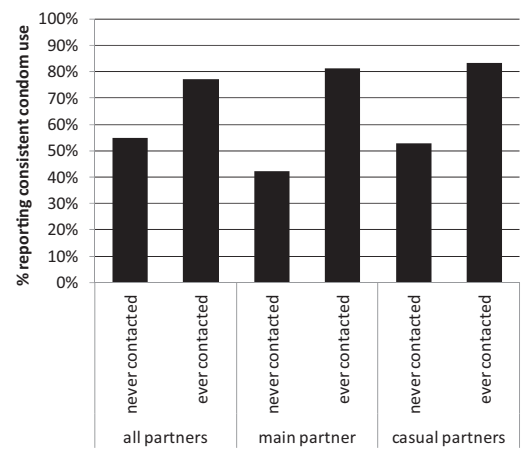

(c) Seen a condom demonstration

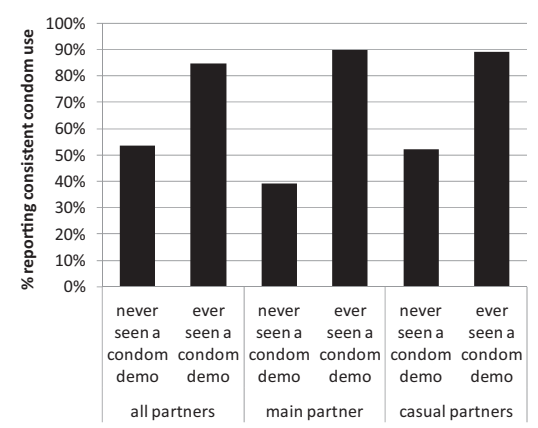

(e) Number of times contacted last month

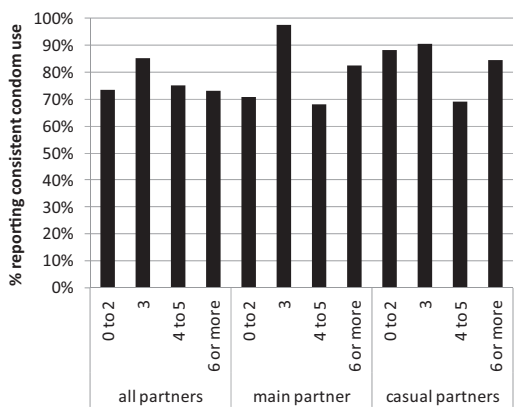

(g) Number of condom

demonstrations seen last month

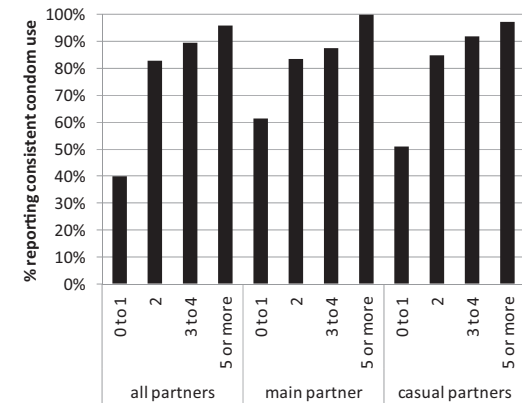

(b) Given condoms

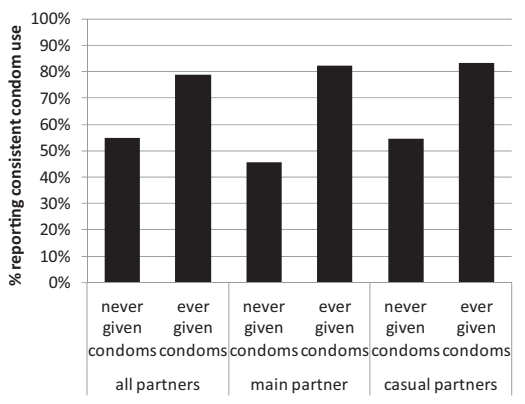

(d) Time since first contacted

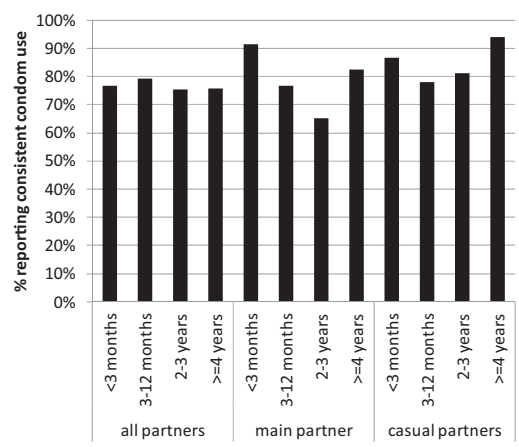

(f) Number of condoms given last time

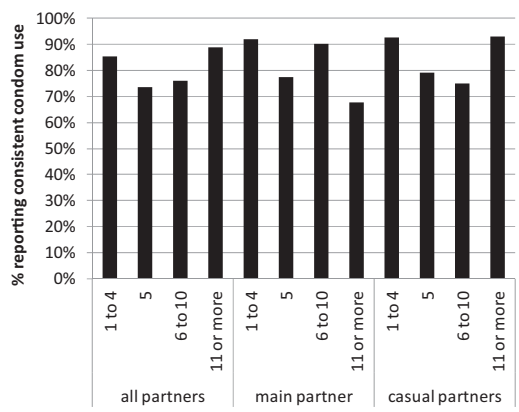

Figure 1 (See legend on next page.) 
(See figure on previous page.)

Figure 1 Levels of reported consistent condom use (CCU) by intervention exposure. CCU is shown with the following different partner types: all, main, casual male sexual partners. CCU is shown for MSM with the following intervention exposures: (a) ever contacted by intervention staff versus not; (b) ever received condoms from the intervention versus not; (c) ever witnessed a condom demonstration versus not; (d) duration since first contacted by the intervention; (e) number of times contacted by the intervention in the last month; (f) number of condoms received from the intervention the last time that they were given condoms; $(\mathbf{g})$ number of condom demonstrations seen in the last month.

month in either unadjusted or adjusted analysis (Figure 1d,e, Table 1). In unadjusted analysis, no relationship was seen between $\mathrm{CCU}$ and number of condoms received, but after adjusting for potential confounders, CCU with the main partner only was found to decrease slightly with increasing number of condoms received (adjusted odds ratio $(\mathrm{AOR})=0.994, \mathrm{p}<0.001)$. CCU with all partner types increased with the number of condom demonstrations seen in the last month in both unadjusted (Figure 1g) and adjusted analyses (for each additional condom demonstration, $A O R=2.15$ for all partners $(p=0.003), 2.11$ for main partner $(p=0.014), 2.06$ for casual partners $(\mathrm{p}=0.024)$; Table 1).

\section{Factors associated with condom use at last sex act}

The percentage of MSM reporting condom use at last sex act was $79 \%$ for sex with any male partner, $78 \%$ with the main partner and $86 \%$ with casual partners.

\section{Associations with socio-demographic and behavioural variables}

Condom use at last sex with any partner was lower among those who had ever been married to a woman $(\mathrm{OR}=0.48, \mathrm{p}=0.06)$, higher among those who had ever sold sex $(p=0.004)$, higher for those for whom sex work was their main source of income $(p=0.04)$, and increased significantly with each additional sex act with casual partners in the past week $(\mathrm{OR}=1.31, \mathrm{p}=0.016)$. Condom use at last sex act with the most recent casual partner was higher amongst those who had ever sold sex $(\mathrm{p}<0.001)$ and amongst those for whom sex work was their main source of income $(\mathrm{p}=0.044)$. Condom use at last sex act was more closely associated with ever selling sex than with sex work as main income source, so 'ever sold sex' was included in multivariable models. Condom use at last sex with the main partner increased significantly with each additional sex act with casual partners in the past week $(\mathrm{OR}=1.32, \mathrm{p}=0.02)$, and was lower among MSM who were Hindus $(\mathrm{p}=0.001)$, circumcised $(\mathrm{p}=0.009)$ or illiterate $(\mathrm{p}=0.08)$.

\section{Unadjusted and adjusted associations with intervention exposure}

As with CCU, condom use at last sex act with all partner types was significantly higher among those ever contacted by the intervention, those ever receiving condoms from the intervention, and among those ever seeing a condom demonstration, in both unadjusted and adjusted analyses (Figure 2a-c, Table 2). Adjusting for sociodemographic and behavioural factors revealed a slight decrease in condom use at last sex with main partners with increasing numbers of condoms received (Table 2). Unlike CCU, a negative association was seen between duration since initial contact with the intervention and condom use at last sex act with both any and main partners (Figure $2 \mathrm{~d}, \mathrm{e}$ ), and this was significant for condom use at last sex act with any partner in adjusted analysis (Table 2). Unlike with CCU, in adjusted analysis, none of the condom use at last sex act variables were significantly associated with number of condom demonstrations seen, and following adjustment for confounders, condom use at last sex act with casual partners was found to increase with the number of condoms received $(\mathrm{AOR}=1.35, \mathrm{p}=0.04$; Table 2).

\section{Discussion}

Our analysis shows that direct contact with the Avahan intervention was associated with increased reported condom use among MSM in Bangalore. MSM reporting any exposure to the intervention had higher condom use than those who did not. Consistent condom use with all male partner types was highest among MSM who had witnessed a condom demonstration, and increased steadily with the number of demonstrations seen. Condom use at last sex act with casual partners was highest among those who had received condoms from the intervention, and increased with the number of condoms received. Condom use did not increase with duration since initial intervention exposure, nor with more frequent contacts with Avahan staff.

The finding that CCU is higher among those exposed to Avahan agrees with similar analyses involving FSWs in Karnataka; however, CCU was higher among FSWs who had been exposed to the intervention for longer [16], which was not seen here. This may be because Sangama, the NGO delivering Avahan services, had been working with MSM for some years previously but only delivering Avahan HIV-prevention services for about eleven months prior to the survey so that duration of contact with Sangama may not accurately reflect duration of Avahan exposure. Although neither factor was associated with condom use, we found that MSM with longer exposure to Sangama also reported more frequent contacts, including over the eleven months for which 
Table 1 Associations between intervention exposure variables and consistent condom use with different partners

\begin{tabular}{|c|c|c|c|c|c|c|c|c|c|c|c|c|}
\hline & \multicolumn{4}{|c|}{ CCU with all partners $(n=305)^{*}$} & \multicolumn{4}{|c|}{ CCU with main partner $(n=122)^{*}$} & \multicolumn{4}{|c|}{ CCU with casual partners $(n=235)^{*}$} \\
\hline & $\mathrm{OR}^{\mathrm{a}}(95 \% \mathrm{Cl})$ & p-value & $\mathrm{AOR}^{\mathrm{b}, \mathrm{c}}(95 \% \mathrm{Cl})$ & p-value & $\mathrm{OR}^{\mathrm{a}}(95 \% \mathrm{Cl})$ & p-value & $\mathrm{AOR}^{\mathrm{b}, \mathrm{d}}(95 \% \mathrm{Cl})$ & p-value & $\mathrm{OR}^{\mathrm{a}}(95 \% \mathrm{Cl})$ & p-value & $\mathrm{AOR}^{\mathrm{b}, \mathrm{e}}(95 \% \mathrm{Cl})$ & p-value \\
\hline \multicolumn{13}{|l|}{ Intervention exposure } \\
\hline $\begin{array}{l}\text { Ever contacted } \\
\text { (versus never) }^{f}\end{array}$ & $2.76(1.41-5.40)$ & 0.004 & $2.65(1.27-5.52)$ & 0.010 & $5.92(1.58-22.23)$ & 0.009 & $8.48(1.90-37.9)$ & 0.006 & $4.43(1.95-10.1)$ & 0.001 & $6.45(2.96-14.1)$ & $<0.001$ \\
\hline $\begin{array}{l}\text { Ever given condoms } \\
\text { (versus never) }^{9}\end{array}$ & $3.10(1.66-5.79)$ & 0.001 & $3.15(1.60-6.22)$ & 0.001 & $5.50(1.57-19.33)$ & 0.009 & $7.90(1.69-37.0)$ & 0.010 & $4.14(1.86-9.2)$ & 0.001 & $5.75(2.56-12.9)$ & $<0.001$ \\
\hline $\begin{array}{l}\text { Ever seen a condom } \\
\text { demo }^{\text {(versus never) }}\end{array}$ & $4.75(2.60-8.68)$ & $<0.001$ & $4.24(2.23-8.07)$ & $<0.001$ & $13.67(4.23-44.17)$ & $<0.001$ & $8.72(2.24-34.0)$ & 0.002 & $7.43(3.30-16.7)$ & $<0.001$ & $7.32(3.26-16.4)$ & $<0.001$ \\
\hline $\begin{array}{l}\text { Duration since first } \\
\text { contact (per year) }\end{array}$ & $0.96(0.79-1.17)$ & 0.707 & $0.87(0.70-1.08)$ & 0.194 & $0.91(0.69-1.20)$ & 0.491 & $0.89(0.71-1.11)$ & 0.294 & $1.06(0.77-1.46)$ & 0.706 & $0.90(0.65-1.26)$ & 0.540 \\
\hline $\begin{array}{l}\text { Number of contacts last } \\
\text { month (per contact)i }\end{array}$ & $0.96(0.91-1.01)$ & 0.115 & $0.97(0.92-1.03)$ & 0.313 & 1.05 (0.95-1.16) & 0.344 & $1.07(0.94-1.21)$ & 0.291 & $0.97(0.92-1.04)$ & 0.391 & $0.98(0.91-1.05)$ & 0.478 \\
\hline $\begin{array}{l}\text { Number of condoms } \\
\text { given last time } \\
\text { (per condom) }\end{array}$ & 1.00 (1.00-1.00) & 0.424 & $1.00(1.00-1.00)$ & 0.956 & $1.00(0.99-1.00)$ & 0.277 & $0.994(0.992-0.997)$ & $<0.001$ & $1.01(0.99-1.02)$ & 0.281 & $1.01(0.99-1.02)$ & 0.304 \\
\hline $\begin{array}{l}\text { Number of condom } \\
\text { demos seen last } \\
\text { month (per time) }\end{array}$ & $1.97(1.30-2.97)$ & 0.002 & $2.15(1.30-3.54)$ & 0.003 & $2.31(1.47-3.63)$ & 0.001 & $2.11(1.18-3.78)$ & 0.014 & $2.13(1.32-3.45)$ & 0.003 & $2.06(1.10-3.86)$ & 0.024 \\
\hline \multicolumn{13}{|c|}{$\begin{array}{l}\text { Odds ratios which are significantly different from } 1 \text { are shown in bold }(\mathrm{p}<0.05) \text {. } \\
\text { *Unadjusted number of people answering questions about condom use with each partner type. Number of individuals included in each analysis may be smaller, de } \\
\text { relating to the intervention exposure under analysis; for continuous exposure variables, unexposed individuals are excluded. } \\
\text { aOR are unadjusted odds ratios. } \\
\text { bAOR are adjusted odds ratios, adjusted for the factors listed below. } \\
\text { CAdjusted for duration as MSM (categorised), sex work as main income, MSM identity (in } 3 \text { groups) and number of times had anal sex with new partners last week. } \\
\text { CAdjusted for religion (Hindu versus other) and number of times had anal sex with new partners last week. }\end{array}$} \\
\hline
\end{tabular}


(a) Intervention contact

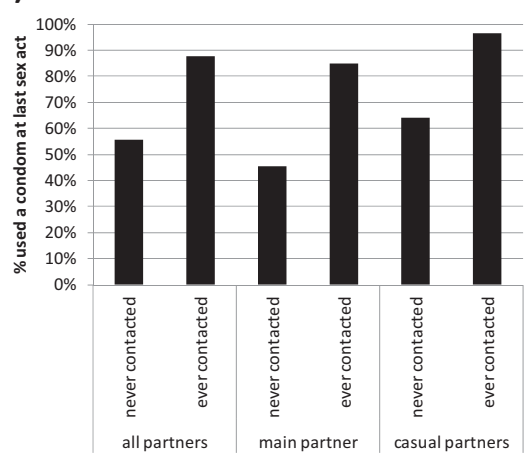

(c) Seen a condom demonstration

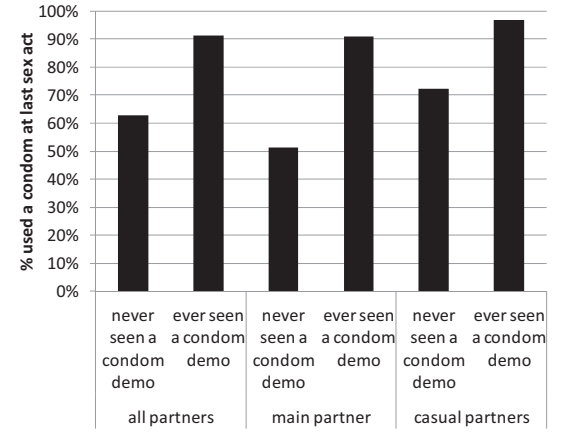

(e) Number of times contacted last month

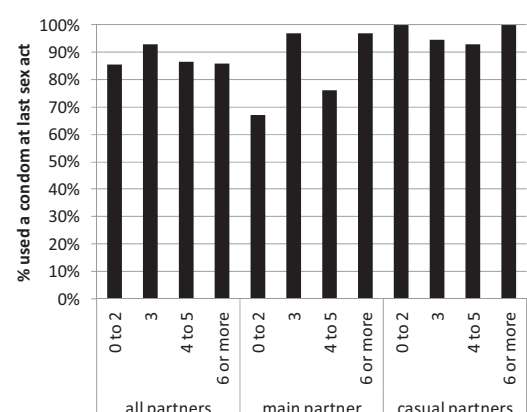

(g) Number of condom

demonstrations seen last month

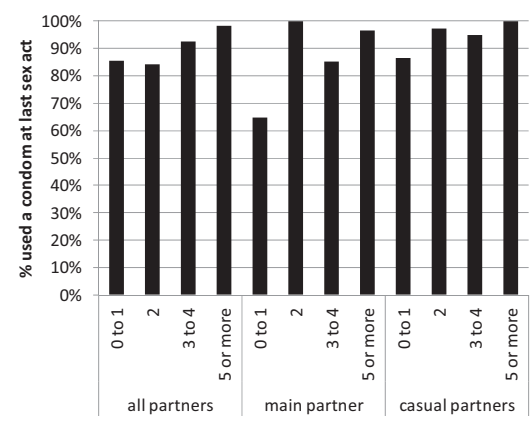

(b) Given condoms

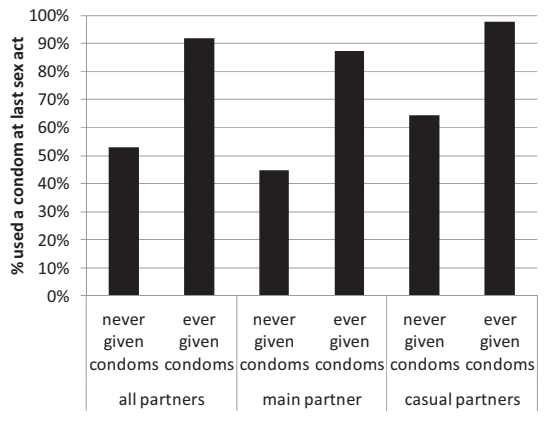

(d) Time since first contacted

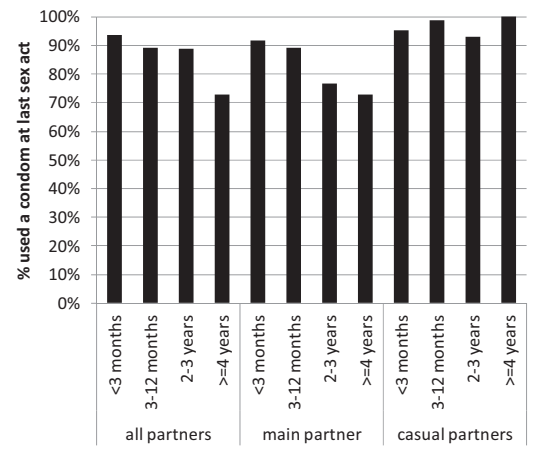

(f) Number of condoms given last time

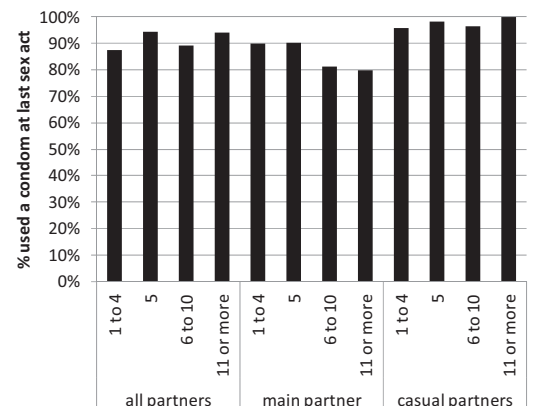


(See figure on previous page.)

Figure 2 Proportion of MSM using a condom at last sex act by intervention exposure. Condom use at last sex act is shown with the following different partner types: all, main and casual male sexual partners. Condom use at last sex act is shown for MSM with the following intervention exposures: (a) ever contacted by intervention staff versus not; (b) ever received condoms from the intervention versus not; (c) ever witnessed a condom demonstration versus not; (d) duration since first contacted by the intervention; (e) number of times contacted by the intervention in the last month; (f) number of condoms received from the intervention the last time that they were given condoms; (g) number of condom demonstrations seen in the last month.

Sangama had delivered Avahan services. One plausible hypothesis for this association is that MSM who contacted the intervention earlier on were more pro-active and more likely to contact the intervention repeatedly.

The strong association between $\mathrm{CCU}$ and the number of condom demonstrations seen was also found among FSWs [16], and contrasts with the lack of positive association between CCU and total number of intervention contacts. In condom demonstrations, MSM are shown and then practise themselves the correct way to unpack condoms and place them on a penis model; condom demonstrations are also used to reinforce risk reduction messages, and to distribute condoms. Thus, a condom demonstration may represent a contact with the program where prevention messages are communicated, as well as giving a direct learning benefit of observing and practising correct condom use [24,25]. Some HIV risk-reduction models propose that behavioural skills, including correct condom use, are a necessary component for individuals' HIV risk-reduction [26]. While the FSW analysis suggested that condom use may saturate for those seeing more than two condom demonstrations per month [16], no saturation effect was seen here for MSM.

The number of condoms received was only positively associated with condom use with casual, not main, partners. Similarly, for FSWs in Karnataka, intervention exposure was associated with increased condom use with commercial, but not main, partners [16]. Counterintuitively, we found a slight decrease in reported condom use (both CCU and condom use at last sex act) with main partners with increasing number of condoms received. While this is of concern, the effect is relatively small (AOR 0.99 per additional condom), and likely to be outweighed by the positive impact on condom use with casual partners, who are more frequently reported by MSM in this sample. Our finding that condom use at last sex act with a casual partner was more strongly associated with receiving condoms from the program than was $C C U$, is consistent with data from other IBBA surveys among MSM across southern India [7]. CCU reflects higher overall, and perhaps longer-term, condom use, which may be less influenced by recent availability of condoms than condom use at last sex act.

Several studies have found increased condom use following behavioural interventions among MSM [27-31]. In agreement with our findings, studies in China found that condom use was associated with receiving condoms and peer education [32], or with reported contact with a prevention program [33].

The data used in this study were collected eight years ago, and while this means that they may not reflect current behaviour (which may be affected by, for example, increased access to ART), they were collected at a time sufficiently soon after the beginning of the Avahan intervention to have a large enough population still unexposed to the intervention allowing for comparisons to be made between exposed and unexposed individuals. In more recent surveys amongst this population [34], the proportion of MSM never contacted by the intervention was greatly reduced, limiting the usefulness of such comparisons.

The high levels of condom use among MSM contacted by the Avahan intervention, coupled with the high levels of contact with the intervention reported, suggest that the Avahan intervention could have a large impact upon HIV transmission amongst MSM in Bangalore. No significant change in HIV prevalence was found amongst MSM in Bangalore between two sero-prevalence surveys carried out in 2006 and 2009 [34], but this does not necessarily mean that Avahan had no impact, as it is possible that HIV prevalence could have risen in the absence of the Avahan program.

\section{Limitations}

Our study used self-reported data, which may be subject to social desirability bias. Social desirability bias is likely to have led to an overestimate of the true impact of the intervention upon condom use in this study, since those exposed to the intervention should have heard more messages promoting condom use than those not exposed, and so may feel a greater pressure to report high condom use. On the other hand, the study may have underestimated the true impact of the intervention upon condom use, since those MSM not directly exposed to the intervention may be having sex with those who have been exposed and are using condoms more frequently. There may have been a selection effect by the intervention, i.e. those reached by Avahan may have been more likely to use condoms anyway. We attempted to control for this by including in our multivariate models measured factors associated with exposure to the intervention, but there may have been other unmeasured factors which could account for both a higher likelihood of intervention 
Table 2 Associations between intervention exposure variables and condom use at last sex act with different partners

\begin{tabular}{|c|c|c|c|c|c|c|c|c|c|c|c|c|}
\hline & \multicolumn{4}{|c|}{ Condom use last sex act with any partner $(n=303)^{*}$} & \multicolumn{4}{|c|}{ Condom use last sex act with main partner $(n=131)^{*}$} & \multicolumn{4}{|c|}{ Condom use last sex act with a casual partner $(n=238)^{*}$} \\
\hline & $\mathrm{OR}^{\mathrm{a}}(95 \% \mathrm{Cl})$ & p-value & $\mathrm{AOR}^{\mathrm{b}, \mathrm{c}}(95 \% \mathrm{Cl})$ & $\overline{p \text {-value }}$ & $\mathrm{OR}^{\mathrm{a}}(95 \% \mathrm{Cl})$ & p-value & $\mathrm{AOR}^{\mathrm{b}, \mathrm{d}}(95 \% \mathrm{Cl})$ & $\overline{p \text {-value }}$ & $\mathrm{OR}^{\mathrm{a}}(95 \% \mathrm{Cl})$ & p-value & $\mathrm{AOR}^{\mathrm{b}, \mathrm{e}}(95 \% \mathrm{Cl})$ & p-value \\
\hline \multicolumn{13}{|l|}{ Intervention exposure } \\
\hline $\begin{array}{l}\text { Ever contacted } \\
\text { (versus never) }^{f}\end{array}$ & $5.82(2.49-13.6)$ & $<0.001$ & $7.55(3.31-17.2)$ & $<0.001$ & $7.15(2.63-19.4)$ & $<0.001$ & $6.75(1.66-27.34)$ & 0.008 & $15.1(6.05-37.5)$ & $<0.001$ & $12.5(4.90-32.0)$ & $<0.001$ \\
\hline $\begin{array}{l}\text { Ever given condoms } \\
\text { (versus never) }^{g}\end{array}$ & $10.0(4.20-24.1)$ & $<0.001$ & $12.2(5.32-28.1)$ & $<0.001$ & $8.48(3.14-22.9)$ & $<0.001$ & $5.81(1.41-24.0)$ & 0.016 & $23.1(7.90-67.5)$ & $<0.001$ & $21.1(6.36-70.0)$ & $<0.001$ \\
\hline $\begin{array}{l}\text { Ever seen a condom } \\
\text { demo (versus never) }\end{array}$ & $6.24(2.68-14.5)$ & $<0.001$ & $5.27(2.41-11.5)$ & $<0.001$ & $9.61(3.34-27.6)$ & $<0.001$ & $6.70(1.46-30.9)$ & 0.016 & $11.0(4.16-29.0)$ & $<0.001$ & $8.76(3.09-24.8)$ & $<0.001$ \\
\hline $\begin{array}{l}\text { Duration since first } \\
\text { contact (per year) }\end{array}$ & $0.78(0.63-0.97)$ & 0.027 & $0.74(0.56-0.98)$ & 0.037 & $0.76(0.60-0.97)$ & 0.026 & $0.85(0.57-1.26)$ & 0.407 & $1.16(0.72-1.87)$ & 0.541 & $1.15(0.69-1.92)$ & 0.592 \\
\hline $\begin{array}{l}\text { Number of contacts last } \\
\text { month (per contact) }\end{array}$ & $0.98(0.91-1.01)$ & 0.476 & $0.93(0.84-1.02)$ & 0.130 & $1.43(0.90-2.27)$ & 0.132 & $1.46(0.91-2.36)$ & 0.115 & $1.12(1.02-1.24)$ & 0.025 & $1.11^{\prime}(0.97-1.27)$ & 0.124 \\
\hline $\begin{array}{l}\text { Number of condoms } \\
\text { given last time } \\
\text { (per condom) }\end{array}$ & $1.00(1.00-1.00)$ & 0.876 & $1.00(1.00-1.00)$ & 0.225 & $1.00(0.99-1.00)$ & 0.156 & $0.993(0.988-0.999)$ & 0.021 & $1.30(0.81-2.11)$ & 0.272 & 1.35 (1.01-1.79) & 0.040 \\
\hline $\begin{array}{l}\text { Number of condom } \\
\text { demos seen last } \\
\text { month (per time) }\end{array}$ & $1.60(1.07-2.39)$ & 0.022 & $1.26(0.75-2.10)$ & 0.378 & $1.56(0.90-2.70)$ & 0.107 & $1.68^{m}(0.62-4.55)$ & 0.301 & $1.88(0.93-3.80)$ & 0.080 & $1.94(0.81-4.66)$ & 0.134 \\
\hline
\end{tabular}

Odds ratios which are significantly different from 1 are shown in bold $(p<0.05)$.

Odds ratios which are significantly different from 1 are shown in bold $(p<0.05)$.
*Unadjusted number of people answering questions about condom use with each partner type. Number of individuals included in each analysis may be smaller, depending upon whether they answered questions relating to the intervention exposure under analysis; for continuous exposure variables, unexposed individuals are excluded.

${ }_{\mathrm{O}}^{\mathrm{a}} \mathrm{OR}$ are unadjusted odds ratios.

${ }^{\mathrm{b}} \mathrm{AOR}$ are adjusted odds ratios, adjusted for the factors listed below.

'Adjusted for duration as an MSM (categorised), whether ever sold sex, whether ever married to a woman, and number of times had anal sex with new partners last week.

${ }^{\mathrm{d} A d j u s t e d ~ f o r ~ r e l i g i o n ~(H i n d u ~ v e r s u s ~ o t h e r), ~ c i r c u m c i s i o n ~ s t a t u s, ~ l i t e r a c y ~(l i t e r a t e ~ v e r s u s ~ n o t) ~ a n d ~ n u m b e r ~ o f ~ t i m e s ~ h a d ~ a n a l ~ s e x ~ w i t h ~ n e w ~ p a r t n e r s ~ l a s t ~ w e e k . ~}$

eAdjusted for whether ever sold sex and number of times had anal sex with new partners last week.

${ }^{\mathrm{f} A O R}$ adjusted for whether ever sold sex.

${ }^{9} \mathrm{AOR}$ adjusted for whether ever paid a female for sex and whether ever sold sex.

${ }^{\mathrm{h}} \mathrm{AOR}$ adjusted for whether ever paid a female for sex and whether ever sold sex.

'AOR adjusted for duration as MSM (categorised) and sex work as main income.

${ }^{\mathrm{j} A O R}$ adjusted for whether ever paid a female for sex, sex work as main income and MSM identity (in 3 groups).

${ }^{\mathrm{k}} \mathrm{AOR}$ adjusted for whether ever married to a woman, ever paid a female for sex and MSM identity (in 3 groups).

'Not adjusted for duration as an MSM, as it overlapped too much with the number of intervention contacts in this subset of the population.

${ }^{\mathrm{m}}$ Not adjusted for circumcision status, as it overlapped too much with religion in this subset of the population. 
exposure and higher condom use. The sampling methods used to gather the data (designed to capture high-risk MSM), and relatively low participation rate, implies that the data may not be representative of the wider MSM population. The analysis used cross-sectional data, and so we cannot demonstrate whether exposure to Avahan preceded increased levels of condom use.

\section{Recommendations}

In light of our findings, we recommend that the Avahan program, and other programs following this model, focus upon providing high-quality contacts with MSM, which wherever possible should include demonstrations of correct condom use and distribution of condoms, as well as communication about risk reduction.

\section{Conclusions}

Reported condom use rates by MSM in Bangalore were higher among those who had been contacted by the Avahan intervention. Consistent condom use was associated with repeated contacts with the program, which involved demonstrations of correct condom use, while condom use at last sex act with casual partners was associated with recently receiving condoms from the program.

\section{Abbreviations \\ AOR: Adjusted odds ratio; CCU: Consistent condom use; FSWs: Female sex workers; MSM: Men who have sex with men; NGO: Non-governmental organization; OR: Odds ratio; STIs: Sexually transmitted infections.}

\section{Competing interests}

The authors declare that they have no competing interests.

\section{Authors' contributions}

KMM carried out the data analysis, led the study design and interpretation of findings, and led the writing of the paper. AMF and PV were involved in the study conception and design, and made a major contribution to the interpretation of findings and writing of the paper. BMR, RW, SI, HJP, KD, JFB, $\mathrm{SM}, \mathrm{CML}, \mathrm{M}-\mathrm{CB}$ and MA provided guidance on local contextualisation for the data analysis and interpretation of findings for the Avahan programme, and provided epidemiological insights and support. All coauthors provided feedback on a draft of the paper, and all authors have read and approved the final manuscript.

\section{Acknowledgements}

The authors would like to thank Parinita Bhattacharjee for providing helpful information about the condom demonstrations.

\section{Funding}

This work was supported by the Wellcome Trust [086431/Z/08/Z]. Funding for the data collection came from the Bill \& Melinda Gates Foundation. The funding bodies played no role in the design, collection, analysis and interpretation of data, in the writing of the manuscript, or in the decision to submit the manuscript for publication. The views expressed herein are those of the authors and do not necessarily reflect the official policy or position of the Wellcome Trust or the Bill \& Melinda Gates Foundation.

\section{Author details}

${ }^{1}$ Department of Global Health and Development, London School of Hygiene and Tropical Medicine, London, UK. ${ }^{2}$ Karnataka Health Promotion Trust, Bangalore, India. ${ }^{3}$ Department of Community Health Sciences, University of Manitoba, Winnipeg, Canada. ${ }^{4}$ Department of Medicine, University of British Columbia, Vancouver, Canada. ${ }^{5}$ Centre for Global Public Health, University of
Manitoba, Winnipeg, Canada. ${ }^{6}$ Public Health England, London, UK. ${ }^{7}$ Centre de recherche du CHU de Québec, Québec, Canada. ${ }^{8}$ Current address: Department of Infectious Disease Epidemiology, Imperial College London, London, UK. ${ }^{9}$ School of Social and Community Medicine, University of Bristol, Bristol, UK.

Received: 1 April 2014 Accepted: 24 November 2014

Published: 4 December 2014

\section{References}

1. Holmes KK, Levine R, Weaver M: Effectiveness of condoms in preventing sexually transmitted infections. Bull World Health Organ 2004, 82(6):454-461.

2. Hughes JP, Baeten JM, Lingappa JR, Magaret AS, Wald A, de Bruyn G, Kiarie J, Inambao M, Kilembe W, Farquhar C, Celum C, and the Partners in Prevention HSV/HIV Transmission Study Team: Determinants of per-coital-act HIV-1 infectivity among African HIV-1-serodiscordant couples. J Infect Dis 2012, 205(3):358-365.

3. Pinkerton SD, Abramson PR: Effectiveness of condoms in preventing HIV transmission. Soc Sci Med 1997, 44(9):1303-1312

4. Weller SC, Davis-Beaty K: Condom effectiveness in reducing heterosexual HIV transmission. Cochrane Database Syst Rev 2002, CD003255.

5. Chandrasekaran P, Dallabetta G, Loo V, Mills S, Saidel T, Adhikary R, Alary M, Lowndes CM, Boily MC, Moore J, for the Avahan Evaluation Partners: Evaluation design for large-scale HIV prevention programmes: the case of Avahan, the India AIDS initiative. AIDS 2008, 22(Suppl 5):S1-S15.

6. Boily MC, Lowndes CM, Vickerman P, Kumaranayake L, Blanchard J, Moses S, Ramesh BM, Pickles M, Watts C, Washington R, Reza-Paul S, Labbe AC, Anderson RM, Deering KN, Alary M, on behalf of the Charme India Team: Evaluating large-scale HIV prevention interventions: study design for an integrated mathematical modelling approach. Sex Transm Infect 2007, 83:582-589.

7. Brahmam GN, Kodavalla V, Rajkumar H, Rachakulla HK, Kallam S, Myakala SP, Paranjape RS, Gupte MD, Ramakrishnan L, Kohli A, Ramesh BM, for the IBBA Study Team: Sexual practices, HIV and sexually transmitted infections among self-identified men who have sex with men in four high HIV prevalence states of India. AIDS 2008, 22(Suppl 5):S45-S57.

8. Solomon SS, Srikrishnan AK, Sifakis F, Mehta SH, Vasudevan CK, Balakrishnan P, Mayer KH, Solomon S, Celentano DD: The emerging HIV epidemic among men who have sex with men in Tamil Nadu, India: geographic diffusion and bisexual concurrency. AIDS Behav 2010, 14(5):1001-1010.

9. Thomas B, Mimiaga MJ, Menon S, Chandrasekaran V, Murugesan P, Swaminathan S, Mayer KH, Safren SA: Unseen and unheard: predictors of sexual risk behavior and HIV infection among men who have sex with men in Chennai, India. AIDS Educ Prev 2009, 21(4):372-383.

10. Kumta S, Lurie M, Weitzen S, Jerajani H, Gogate A, Row-kavi A, Anand V, Makadon $\mathrm{H}$, Mayer $\mathrm{KH}$ : Bisexuality, sexual risk taking, and HIV prevalence among men who have sex with men accessing voluntary counseling and testing services in Mumbai, India. J Acquir Immune Defic Syndr 2010, 53(2):227-233

11. Saidel T, Adhikary R, Mainkar M, Dale J, Loo V, Rahman M, Ramesh BA, Paranjape RS: Baseline integrated behavioural and biological assessment among most at-risk populations in six high-prevalence states of India: design and implementation challenges. AIDS 2008, 22(Suppl 5):S17-S34.

12. Pickles $M$, Foss $A M$, Vickerman $P$, Deering $K$, Verma $S$, Demers $E$, Washington R, Ramesh BM, Moses S, Blanchard J, Lowndes CM, Alary M, Reza-Paul S, Boily MC: Interim modelling analysis to validate reported increases in condom use and assess HIV infections averted among female sex workers and clients in southern India following a targeted HIV prevention programme. Sex Transm Infect 2010, 86(Suppl 1):|33-143.

13. Lowndes CM, Alary M, Verma S, Demers E, Bradley J, Jayachandran AA, Ramesh BM, Moses S, Adhikary R, Mainkar MK: Assessment of intervention outcome in the absence of baseline data: 'reconstruction' of condom use time trends using retrospective analysis of survey data. Sex Transm Infect 2010, 86(Suppl 1):149-155.

14. Bradley J, Moses S, Blanchard JF, Rajaram S, Ramesh BM, Verma S, Alary M: Assessing reported condom use among female sex workers in southern India through examination of condom availability. Sex Transm Infect 2010, 86(Suppl 1):|44-|48. 
15. Dureau J, Boily MC, Vickerman P, Pickles M, Isac S, Ramesh B, Verma S, Moses S, Alary M, Kalogeropoulos K: What has been the effect of the Avahan HIV intervention on condom use among female sex workers? Insights from a fully Bayesian inference methodology [Abstract]. Sex Transm Infect 2011, 87(Suppl 1):A197-A198.

16. Deering K, Boily M-C, Lowndes C, Shoveller J, Tyndall M, Vickerman P, Bradley J, Gurav K, Pickles M, Moses S, Ramesh B, Washington R, Rajaram S, Alary M: A dose-response relationship between exposure to a large-scale HIV preventive intervention and consistent condom use with different sexual partners of female sex workers in southern India. BMC Public Health 2011, 11(Suppl 6):S8.

17. Boily M-C, Pickles M, Lowndes CM, Ramesh BM, Washington R, Moses S, Deering KN, Mitchell KM, Reza-Paul S, Blanchard J, Vassall A, Alary M, Vickerman P: Positive impact of a large-scale HIV prevention program among female sex workers and clients in Karnataka state, India. AIDS 2013, 27(9):1449-1460.

18. Pickles M, Boily M-C, Vickerman P, Lowndes CM, Moses S, Blanchard JF, Deering KN, Bradley J, Ramesh BM, Washington R, Adhikary R, Mainkar M, Paranjape RS, Alary M: Assessment of the population-level effectiveness of the Avahan HIV-prevention programme in South India: a preplanned, causal-pathway-based modelling analysis. Lancet Glob Health 2013, 1(5):e289-e299.

19. Panovska-Griffiths J, Vassall A, Prudden HJ, Lépine A, Boily M-C, Chandrashekar S, Mitchell KM, Beattie TS, Alary M, Martin NK, Vickerman P: Optimal allocation of resources in female sex worker targeted HIV prevention interventions: model insights from Avahan in South India. PLoS One 2014, 9(10):e107066

20. Indian Council of Medical Research \& Family Health International: National Interim Summary Report - India, Integrated Behavioural and Biological Assessment (IBBA), Round 1 (2005-2007). New Delhi: 2007.

21. Asthana $S$, Oostvogels $R$ : The social construction of male 'homosexuality' in India: implications for HIV transmission and prevention. Soc Sci Med 2001, 52(5):707-721.

22. Boyce P: 'Conceiving kothis': men who have sex with men in India and the cultural subject of HIV prevention. Med Anthropol 2007, 26(2):175-203.

23. Phillips AE, Boily MC, Lowndes CM, Garnett GP, Gurav K, Ramesh BM, Anthony J, Watts R, Moses S, Alary M: Sexual identity and its contribution to MSM risk behavior in Bangaluru (Bangalore), India: the results of a two-stage cluster sampling survey. J LGBT Health Res 2008, 4(2-3):111-126.

24. Kolb DA: Experiential Learning: Experience as the Source of Learning and Development. New Jersey: Prentice-Hall; 1984.

25. Calsyn DA, Hatch-Maillette MA, Doyle SR, Cousins S, Chen T, Godinez M: Teaching condom use skills: practice is superior to observation. Subst Abus 2010, 31(4):231-239.

26. Fisher JD, Fisher WA: Changing AIDS-risk behaviour. Psychol Bull 1992 111(3):455-474.

27. Herbst JH, Sherba RT, Crepaz N, Deluca JB, Zohrabyan L, Stall RD, Lyles CM: A meta-analytic review of HIV behavioral interventions for reducing sexual risk behavior of men who have sex with men. J Acquir Immune Defic Syndr 2005, 39(2):228-241.

28. Huang Z, Wang M, Fu L, Fang Y, Hao J, Tao F, Tu C: Intervention to increase condom use and HIV testing among men who have sex with men in China: a meta-analysis. AIDS Res Hum Retroviruses 2013, 29(3):441-448

29. Zheng $L$, Zheng $Y$ : Efficacy of human immunodeficiency virus prevention interventions among men who have sex with men in China: a meta-analysis. Sex Transm Dis 2012, 39(11):886-893.

30. Herbst JH, Beeker C, Mathew A, McNally T, Passin WF, Kay LS, Crepaz N, Lyles CM, Briss P, Chattopadhyay S, Johnson RL: The effectiveness of individual-, group-, and community-level HIV behavioral risk-reduction interventions for adult men who have sex with men: a systematic review. Am J Prev Med 2007, 32(4 Suppl):S38-S67.

31. Johnson WD, Diaz RM, Flanders WD, Goodman M, Hill AN, Holtgrave D, Malow R, McClellan WM: Behavioral interventions to reduce risk for sexual transmission of HIV among men who have sex with men. Cochrane Database Syst Rev 2008, 3, CD001230.

32. Liu J, Qu B, Ezeakile MC, Zhang Y: Factors associated with unprotected anal intercourse among men who have sex with men in Liaoning Province, China. PLoS One 2012, 7(11):e50493.
33. Ye S, Xiao $Y$, Jin C, Cassell H, Blevins M, Sun J, Vermund SH, Qian HZ: Effectiveness of integrated HIV prevention interventions among Chinese men who have sex with men: evaluation of a 16-city public health program. PLoS One 2012, 7(12):e50873.

34. Indian Council of Medical Research \& Family Health International: National Summary Report - India (July 2011), Integrated Behavioural and Biological Assessment (IBBA), Round 2 (2009-2010). New Delhi: 2011.

doi:10.1186/1471-2458-14-1245

Cite this article as: Mitchell et al:: Relationship between exposure to the Avahan intervention and levels of reported condom use among men who have sex with men in southern India. BMC Public Health 2014 14:1245.

\section{Submit your next manuscript to BioMed Central and take full advantage of:}

- Convenient online submission

- Thorough peer review

- No space constraints or color figure charges

- Immediate publication on acceptance

- Inclusion in PubMed, CAS, Scopus and Google Scholar

- Research which is freely available for redistribution

Submit your manuscript at www.biomedcentral.com/submit
C BioMed Central 